\title{
Possibilidades e dificuldades nas relações entre ciências sociais e epidemiologia
}

\author{
Possibilities and difficulties in the relationships \\ between social sciences and epidemiology
}

M aria Cecília de Souza M inayo 1

Simone Gonçalves de Assis 1

Suely Ferreira Deslandes 1

Edinilsa Ramos de Souza 1

\footnotetext{
1 Centro Latino-

Americano de Estudos de Violência e Saúde Jorge Careli - Claves, Fiocruz.

Av. Brasil 4036, sala 700 $M$ anguinhos, 21045-900, Rio de Janeiro RJ. cecilia@claves.fiocruz.br
}

Abstract This article aims to establish a theoretical discussion about difficulties and possibilities of articulations between epidemiol ogy and social science in public health. The authors, through reflexive method, consider ways of possibilities for one main question: how had been appropriated concepts and categories from one discipline to the other? They present as essential for the articulation the will of the researchers to dialogue; the theoretical disciplinary exercise as such as dialogue between them; the understanding of the disciplinary logics that give sense to the concepts. They finish, exemplifying the limits and advances in the appropriation of the interdisciplinarity, from results of some research, mainly on violence and health.

Key words Epidemiology, Social sciences, Interdisciplinarity
Resumo 0 artigo objetiva efetuar uma discussão teórica sobre as dificuldades e possibilidades de articulação entre epidemiologia e ciências sociais no campo da saúde pública. As autoras, através de método reflexivo, problematizam e propõem caminhos de possibilidades ante a principal indagação do texto que é como têm sido apropriados os concei tos e categorias de uma disciplina pela outra. A presentam como essencial para a articulação a disposição dos pesquisadores de dialogarem; 0 exercício teórico disciplinar tanto quanto o diálogo entre elas; a compreensão das lógicas disciplinares que dão sentido aos conceitos. Finalizam, discutindo os limites eavanços na apropriação da interdisciplinaridade, a partir de exemplos de algumas áreas, especialmente de pesquisas sobre violência e saúde.

Palavras-chave Epidemiologia, Ciências sociais, Interdisciplinaridade 


\section{Introdução}

N este artigo propomos introduzir a necessária discussão das relações entre epidemiologia e ciências sociais na composição do campo da saúde pública. Fizemos muitas leituras sobre o assunto, o que pode ser constatado pela vasta bibliografia aqui citada. No entanto, a maioria dos textos fala mais a partir de um lado: a dificuldade dos epidemiologistas em se apropriarem corretamente das categorias e conceitos das ciências sociais. E pouco se referem ao distanciamento desses últimos dos referenciais da saúde. Ainda que na forma de tentativa, pretendemos abordar os dois lados. Nós, as autoras deste texto, no cotidiano dos processos de pesquisa, vimos tentando fazer um trabalho real de articulação entre esses campos de conhecimento, e temos experimentado, na práti$\mathrm{ca}$, a fertilidade dessa tentativa e as dificuldades para conseguir um resultado transdisciplinar. Com base em $\mathrm{H}$ abermas (1987), entendemos que o segredo desse desafio está exatamente no fato de se discutir e aprofundar conceitos aparentemente semel hantes de várias disciplinas diferentes, referindo-se aos mesmos objetos. A partir da experiência, não consideramos possível tratar in totum a aproximação de duas disciplinas, mas nos parece exeqüível trabal har com problemas conceituais que permitam discussões sobre temas concretos. Acrescentamos ainda que essa articulação não é natural, não se produz pelo senso comum e necessita ser problematizada.

Nos trabalhos que o Claves vem produzindo (Assis, 1999; Assis \& Constantino, 2001; Minayo et al., 2000; M inayo, 2000; Souza \& M inayo, 2001; Deslandes e Assis, 2002) geralmente nossa atenção teórica tem sido dirigida para as necessidades de Triangulação de M étodos (M inayo \& Cruz N eto, 1999). Aliás, essa tendência não é incomum, pois numa revisão bibliográfica sobre textos mais recentes, descobrimos que assim trabalham ou discutem vários autores. É o caso, por exemplo, de Czeresnia e colaboradores (2000) que elaboraram um debate sobre o tema na revista $\mathrm{H}$ istória, Ciência e Saúde em que ressaltam a importância da relação complementar entre epidemiologia e antropologia tendo em vista a integração metodológica das pesquisas em saúde. Também tratam 0 assunto do ponto de vista instrumental, chamando a atenção para as possibilidades e potencialidades do uso de abordagens epidemiológicas e antropológicas rápidas, na avalia- ção de programas e serviços. I gualmente relembram atividades de campo, de cunho epidemiológico em que se utilizaram de abordagens empáticas de aproximação, próprias da antropologia, como de muita utilidade para a compreensão de problemas de saúde. N esse debate apenas uma vez é mencionada a necessidade de aprofundamento de questões conceituais.

Duas perguntas poderiam dirigir nossa reflexão. A primeira seria: como vêm sendo apropriadas categorias das ciências sociais pela epidemiologia, disciplina que historicamente tem ocupado posição dominante na área da saúde coletiva? Por outro lado, como vêm sendo incorporadas as categorias da área de epidemiologia pelas ciências sociais? Para, a seguir, problematizar e propor caminhos de possibilidade de articulação. É sobre essas indagações que pretendemos discorrer no presente artigo.

\section{Apropriação de categorias sociológicas pela epidemiologia}

H istoricamente, podemos observar que as relações entre epidemiologia e ciências sociais vêm se construindo na convivência com, pelo menos, três modelos de explicação das doenças: a de tipo organicista, que confere existência independente à saúde e enfermidade, e cujo modelo mais radical é o da teoria microbiana que se vangloriava de poder superar todas as ideologias políticas e interpretações sociais que minavam o campo da cientificidade da medicina ( N unes, 1985). Sua versão mais atual se encontra nas áreas mais avançadas das pesquisas básicas e aplicadas da genética, que prometem a utopia da "saúde perfeita" de forma independente dos processos sociais, segundo Sfez (1997). O utro modelo articula saúde e doença com condições de vida, cujos exemplos na modernidade podem ser encontrados em John Snow (1967) e M ckeown \& Löwe (1979). Esse modelo torna-se específico e radical na proposta paradigmática da epidemi ologia social, especial mente forte na América Latina nas últimas décadas do século 20 (Breilh, 1979; Laurell, 1977). No Brasil, a discussão da eqüidade social e a necessidade de incorporação deste tema nas análises epidemiológicas deram impulso a esse tipo de abordagem, também denominado pelos seus adeptos como "epidemiologia crítica", e aos estudos da área de saúde, trabaIho e ambiente (Carvalho, 2002). No momen- 
to, presenciamos o crescimento de uma outra linha explicativa, mais ampliada, denominada abordagem ecossistêmica de saúde, que tenta contextualizar a epidemiologia das enfermidades com as condições sociais que as determinam ou influenciam na sua ocorrência e, também, dentro do contexto ambiental. Seu fundamento, embora muito mais complexo, remonta às teorias ecológicas e multicausais das enfermidades (Waltners-Toews, 2001; Forget $\&$ Lebel, 2001; M inayo, 2002).

Tradicionalmente, as correntes explicativas dos processos de adoecimento baseiam-se nos três principais pilares da epidemiologia atual (Pereira, 2000): ciências biológicas, sociais e estatística (incluindo-se as ciências matemáticas e a demografia). Entretanto, a ênfase predominante recai principalmente sobre as ciências biológicas e a estatística. Carvalho (2002) lembra que inicialmente o status de cientificidade da epidemiologia era dado pela descrição anatomofisiológica, microbiológica e parasitológica detalhada da mediação do processo patológico. Posteriormente, com a sofisticação da análise estatística e o emprego da informática, a epidemiologia dos fatores de risco adquire quase exclusi vidade como produção científica da área [epidemiologia] e chega mesmo a defini-la. Ressalta ainda que a adoção da estatística pel os sanitaristas brasileiros se intensificou nas décadas de 1960 e 1970, mas que não foi acompanhada pela incorporação de métodos e técnicas das ciências sociais.

N ossa hipótese é de que, no caso da epidemiologia, na maioria das vezes, a inserção das teorias sociais se dá por meio da apropriação dos termos de forma ideológica ou de senso comum. I sso acontece não apenas no momento da redução de conceitos a variáveis, mas também na incorporação superficial e acrítica de marcos teóricos. Essas distorções teóricas são referidas por Pereira (2000), que constata a necessidade fundamental de a epidemiologia melhorar e tornar complexo o conhecimento sobre a interação do social com o biológico.

$\mathrm{N}$ a verdade, o tema que abordamos tem sido constante, embora intermitente no campo reflexivo da epidemiologia. Lembramos, por exemplo, o importante texto de Goldberg (1990) sobre as relações entre a epidemiologia e os determinantes socioeconômicos da saúde. Para este trabalho, 0 autor reviu mais de 90 estudos, na sua maioria realizados em primeiro lugar na França, e em segundo, nos Estados Unidos e Inglaterra, que incorporam esses de- terminantes ou que se reduzem ao tecnicismo do método. Goldberg mostra em sua análise que a tendência maior da disciplina é a marginalização dos fatores sociais, ou, quando muito, a apropriação de problemas sociais como variáveis.

Numa compilação de referências denominada Bases históricas da epidemiologia, Almeida Filho (1989) detalha o processo de construção dessa disciplina, numa escalada rumo ao quantitativismo e à abordagem tecnicista: (a) ela remonta a uma apropriação da Aritmética política de William Petty e dos levantamentos de Estatística médica de John Graunt no século 17 (Last, 1983); b) articula-se aos estudos pelo método numérico para conhecimento da incidência e prevalência de doenças na França, nos Estados Unidos e na Inglaterra, no século 19 (Lilienfeld, 1976); c) é filha da institucionalização da estatística médica, na Inglaterra, a partir do trabalhos de William Farr, que, em 1839, criou o registro anual de mortalidade e morbidade para a Inglaterra e o País de Galles (Last, 1983), mas só se institucionaliza vindo a ser ensinada como disciplina nas universidades já no século 20. M acM ahon et al. (1969) nos brindaram com seu primeiro manual de Epidemiologia na década de 1960.

Almeida Filho (1989) comenta também que Major Geenwood, no período de 1888-1949, sendo o primeiro professor de epidemiologia da London School, tornou-se o principal responsável pela introdução do raciocínio estatístico na epidemiologia, rejeitando o caráter compreensivo das investigações. Essa busca de cientificidade positivista na disciplina nascente e na construção da própria história da epidemiologia ocorreu pari passu com a revolução bacteriana. 0 extraordinário desenvolvimento da bacteriologia, no final do século 19 e início do século 20, provocou um inegável fortalecimento da medicina organicista, contrariando as tentativas da chamada medicina social e política, que, naquele mesmo período, tentava buscar os nexos entre 0 aparecimento das doenças e as questões sociais. Assim, a epidemiologia quantitativista passou a se destacar da saúde pública, refletindo o diagnóstico médico ontológico e nosológico da história natural das doenças. No entanto, o contrário também ocorreu e Almeida Filho (1989) o registra: a versão britânica da medicina social evoluiu para uma vertente pretensamente técnica, constituindo a chamada saúde pública.

Chamamos atenção para a simbiose teórica 
que desde então se processa entre o que é saúde pública e o que é epidemiologia: essa espécie de "sinonímia" presente em textos, debates e congressos da área e manifestando-se ora sob a forma de redução, ora sob a forma de expansão. De um lado, os reducionistas privilegiam a visão técnica e biológica da distribuição das doenças na população. De outro, os expansionistas, cuja racionale teórica bebe na fonte originária da medicina social do século 19 ( $\mathrm{Nu}$ nes, 1999), juntam e articulam conceitos e mé todos da epidemiologia e das ciências sociais. Alguns desses últimos conseguem êxitos na apropriação das teorias sociológicas, outros as incorporam de forma naturalizada e mecânica.

A epidemiologia de viés tecnicista difere também da que era realizada pelos tropicalistas das décadas de 1930, 1940, uma vez que tratavam a doença de forma coletiva, situando- a em uma área endêmica. Estavam interessados em ciclos dinâmicos de populações. Esse modelo praticamente desapareceu depois da década de 1960, obscurecido que foi pelo pragmatismo das campanhas sanitárias para a erradicação de doenças. E hoje, do ponto de vista técnico, domina o modelo da vigilância epidemiológica.

0 caso brasileiro elatino-americano, na busca de articulação de categorias das ciências sociais à epidemiologia, é bastante inter essante. Reagindo ao tecnicismo eao biologicismo da medicina e da epidemiologia tradicional, surgiu nos anos 70 uma corrente de pensamento propondo pensar saúde e doença por meio da sua história social, sob o olhar do marxismo em seu viés estrutural. Como foco central de análise foi adotada a desigualdade da repartição dos bens e das condições de vida e, consequentemente, da saúde e doença na sociedade de classes. Essa corrente está hoje em declínio, acompanhando a crise do marxismo na sociedade ocidental e no pensamento sociológico.

Numa apresentação esquemática, Almeida Filho em Epidemiologia sem números (1989) coloca assim a abrangência do Campo de Epidemiologia, evidenciando as dificuldades de sua definição: 0 bjeto da clínica $\Rightarrow$ objeto fisiopatológico + determinantefisiopatológico. Objeto epidemiológico $\Rightarrow$ determinante clínico + determinante epidemiológico. 0 bjeto das ciências sociais $\Rightarrow$ determinante epidemiológico + determinante social (ambos objetos da ciência da história).

Ora, se há um sucessivo envolvimento dos objetos e dos determinantes, é verdade também que a representação do campo social co- mo o que abrange a totalidade das manifestações de saúde e enfermidade não é suficiente: 0 social está simultaneamente na própria produção fisiopatológica e epidemiológica, permeando e modificando suas manifestações e não apenas Ihes dando continência. Por isso, ressaltando as dificuldades de conceituação, o próprio Almeida Filho (1989) diz que "será sempre redundante qual quer referência a uma epidemiologia social".

Essa última observação coloca em xeque uma importante questão epistemológica trazida pela proposta historicamente datada da epidemiologia social e do seu forte envolvimento com o pensamento marxista mecanicista, cujos exemplos, da década de 1970 e metade da de 1980, podem ser encontrados em trabalhos de Breilh (1979) e Breilh \& Granda (1985) e Laurell (1977). Costa \& Costa (1990) criticam, de forma contundente, essa apropriação reducionista, numa análise sobre o ostracismo a que foi relegado John Snow, pelos epidemiologistas sociais. Entendemos que a epidemiologia social fez uma espécie de mediação entre a visão positivista da epidemiologia descritiva e 0 determinismo, também positivista, do marxismo althusseriano. Transitou nos dois campos, sem conseguir se desprender das correntes fundamentadas na filosofia da consciência (ou seja, da observação exterior dos fenômenos), abordando a questão social ora como um cenário de produção das doenças, ora como um determinante, sem mediações, das situações, dos comportamentos e dos sujeitos. Como a epidemiologia positivista, a epidemiologia social pouco levou em conta as questões da subjetividade, das relações e os processos microssociológicos do mundo da vida, como complexificadores das expressões de saúde e doença no híbrido biológico-social. Ao não considerar relações e subjetividade, os epidemiologistas sociais perdem duas categorias essenciais do pensamento marxista clássico: especificidade histórica e diferenciação interna dos processos sociais.

É interessante observar que, além de Almeida Filho, vários autores reconhecidos pela reflexão epistemológica têm sido críticos das contribuições efetivas da epidemiologia social. Barreto (1990) comenta: (...) Suas contribuições têm sido limitadas (...) por problemas conceituais e metodológicos não solucionados (...) e por fatores externos à disci plina, relacionados ao baIanço político na América Latina. Costa \& Costa (1990) questionam o uso linear da obra de En- 
gels, Sobre a situação da classe trabalhadora na Inglaterra (1977), como se esse autor houvesse escrito para os sanitaristas, quando, mesmo le vando em conta todo o val or de sua obra, seu texto tem como base as teorias miasmáticas. Ressaltam, também, a impropriedade da transposição simples do materialismo histórico como método de análise dos problemas de saúde.

Constatamos que, no processo de construção da epidemiologia, fazem falta teorias de médio alcance, como refere M erton (1970) a propósito da própria sociologia. Isso leva a que os pensadores, no esforço de construção, se deixem trair pela linguagem, confundindo ciência, disciplina (termo mais amplamente aceito eincorporado) e método. U m dos muitos exemplos dessa falta de precisão conceitual é o de Almeida Filho (1989) quando diz: com tudo isso, a epidemiologia é uma boa ferramenta, cabendo-nos usá-la da melhor forma, conscientes dos seus limites. 0 pinião bastante diferente manifesta o mesmo autor, quando inicia sua obra A ciência da saúde (2000) (resumo de seu memorial para professor titular da UFBA) dizendo: proponho que, na atualidade, somente a epidemiologia revela potencial epistemológico e metodológico para ser intitulada ciência da saúde.

Apenas como exemplificação do persistente debate que se mantém na área, relembramos que para Almeida Filho (1989) o objeto da epidemiologia deriva da clínica; é um objeto intermediário, servindo de ligação entreo individual e o coletivo. M acM ahon e colaboradores (1969) o definem pelo método. M iettinen (1985) o identifica na relação de uma medida de ocorrência a um ou mais determinantes. E Gonçalves (1990) indaga se a epidemiologia ecológica não seria capaz de fundar uma disciplina científica com objeto próprio, seguindo o caminho da epidemiologia social.

Em síntese, concluímos que as duas formas mais comuns de absorção dos conceitos sociológicos usados para a análise de contexto dos processos de saúde/enfermidade têm sido seu uso ideológico e sua instrumentalização. No primeiro caso, além de considerar a epidemiologia social como a própria saúde pública, a abordagem marxista da epidemiologia tomou uma determinada vertente do marxismo como a totalidade da "ciência social". D esta forma, nessa tentativa histórica ocorreu um paradoxo: de um lado, um alto nível de abstração das análises da realidade pelo uso dos esquemas macrossociais e até anti-antropológicos quando adotados dentro do viés althusseriano (Cos- ta \& Costa, 1990; M inayo, 2001). De outro, a busca crescente de aperfeiçoamento e de aproximação dos métodos e das técnicas bioestatísticas para explicações epidemiológicas. No meio foi gerado um vazio interpretativo dos processos biossociais vivenciados no cotidiano.

No tratamento dos conceitos sociais de forma instrumentalizada os exemplos são maioria. A título de ilustração, citamos uma das constatações da recente revisão realizada por Souza \& M inayo (2001) sobrea produção científica da década de 1990, referente ao tema da "violência e acidentes". M etade dos trabalhos de epidemiologia sobre o assunto não apresenta nenhuma teorização, sendo apenas estudos de cunho metodológico, descritivo e classificatório de dados secundários ou primários. As categorias sociais aí aparecem reificadas e como entidades com existência em si mesmas. Ora, isso repete e aprofunda o viés tecnicista que vem sendo tratado historicamente, sobre o qual assim se pronuncia Goldberg (1990) (...) 0 resultado observado mostra a posição marginal da abordagem [socioeconômica nos estudos]. 0 interesse concedido a tais fatores é fraco (...) e vai decrescendo regularmente, e esse decréscimo é estatisticamente significativo.

Para al guns autores, a impossibilidade de trabal har com os fatores sociais é uma questão epistemológica, como se evidencia no artigo intitulado "Social epidemiology? N o way", publicado em importante periódico científico, o International J ournal of Epidemiology (Zielhuis \& Kiemeney, 2001), em que os autores restringem a epidemiologia ao campo médico. Justificam a recusa da incorporação das ciências sociais pela dificuldade ostentada pela epidemiologia em identificar os mecanismos que explicam a relação entre ambiente social e determinantes de saúde. Embora este artigo tenha suscitado várias réplicas em prol de uma epidemiologia que problematize os componentes sociais dos problemas que estuda, o texto ilustra as dificuldades de maior interlocução entre as diferentes áreas da saúde.

Chamar atenção para esse fato é retomar a discussão inconclusa sobre o reducionismo acadêmico, quando se acredita que a verdade está nos "dados" ou "no uso correto do método". Essa postura leva muitos pesquisadores a produzirem informações cujo campo de contextualização são seus resultados, não havendo perguntas e reflexões prévias que informem sobre elas. 0 mal-estar em relação a esse fetichismo do método é também apresentado por epi- 
demiologistas como Sabroza (1990), Costa (1990), e Gonçalves (1990). E Carvalho (2002) assim o resume, tomando como ponto de partida 0 modelo tradicional de ocorrência de doenças utilizado pela epidemiologia: dificilmente ele permite a descrição de qualquer estrutura epidemiológica, pois ao privilegiar a descrição do processo fisiopatológico e manter o meio ambiente como uma caixa-preta de vagos contornos, impede o uso, pela epidemiologia, dos métodos e técnicas das ciências sociais. Esse impasse na articulação do conhecimento social na epidemiologia está refletido, recentemente, no capítulo de introdução de dois importantes livros brasileiros que servem de base à formação de uma nova escola de epidemiologistas ( $\mathrm{Me}$ dronho et al., 2002; Pereira, 2000).

\section{Apropriação da epidemiologia pelas ciências sociais}

Por sua parte a introdução das ciências sociais no campo de construção da saúde pública é bastante problemática. A partir de uma crítica profunda ao tecnicismo da epidemiologia, Goldberg assim se refere ao distanciamento das ciências sociais na abordagem dos problemas de saúde: por sua vez, os economistas e sociólogos são produtores de teorias nas quais os fenômenos da saúde são ignorados, [como por exemplo] estudam problemas de financiamento dos gastos de saúde, sem referência epidemiológica. $\mathrm{H}$ istoricamente sabemos que a entrada dos profissionais das ciências sociais no campo da saúde se fez de forma caudatária, por causa da hegemonia histórica da medicina. Embora a reflexão sobre a interferência dos aspectos econômicos, políticos e sociais sobre a saúde seja antiga e tenha florescido desde a metade do sé culo 18 , a racionalidade médica sempre predominou nas tentativas de formalização teórica da área. Os termos referentes ao social nunca mereceram aprofundamento conceitual e, quando usados, freqüentemente foram apropriados de forma acrítica.

Foi já no século 20 que, conta Nunes (1985), os sociólogos, antropólogos e psicólogos foram chamados, como profissionais, a integrar o campo de saúde. Num primeiro momento dominou o viés condutivista e funcionalista de seus trabalhos, respondendo à demanda do campo médico, para que fossem propiciadas chaves de compreensão dos códigos diferentes com os quais os leigos concei- tuam e vivenciam os processos de saúde e doença, acessam aos serviços, e representam os tratamentos. Ou ainda, aos cientistas sociais foi pedido que fornecessem análises mais aprofundadas das "variáveis sociais" da história das doenças. Até hoje, muito do que é feito nos países subdesenvolvidos com financiamento de organizações internacionais conserva a mesma dinâmica de subalternidade das ciências sociais em relação ao campo médico.

M as também nas ciências sociais a lógica tecnicista, que se irradiou a partir dos Estados U nidos, sobretudo a partir da Segunda Guerra M undial, é imperante e hegemônica. Assim a confusão entre cientificidade e quantificação, no campo da epidemiologia, não é um privilégio dessa disciplina. A abordagem estatística positivista foi igualmente privilegiada desde os clássicos trabalhos de Durkheim, sobretudo em Regras do método sociológico, passando pela influência de Stouffer (1931), na chamada Escola de Colúmbia, e vem até os atuais analistas sociais, aqui e al hures. D evendo se firmar no campo dominado pelo cientificismo da hard science, as ciências sociais e humanas, historicamente, têm elaborado proposições, conceitos e categorias capazes de dar consistência a universos teóricos que privilegiam a abordagem estatística positivista dos fenômenos.

No caso brasileiro, a presença dos cientistas sociais no campo da saúde é relativamente recente, de tal modo que a história de sua inserção sistemática tem pouco mais que 30 anos (Nunes, 1985; Canesqui, 1998; N unes, 1999; M inayo, 2000). A maioria, nos anos 70 e 80, seguiu a linha acadêmica mais geral na sociologia nacional, distinguindo-se pela realização de análises macrossociais; institucionais; e de estudos a partir de dados secundários e documentais. Algumas se destacam pelas contribuições epistemológicas e sociológicas e outras pelas análises das políticas do setor. É interessante observar que, antes dos anos 80 , raros eram os cientistas sociais da saúde que iam a campo e realizavam trabalhos empíricos com a população. A revisão bibliográfica de N unes (1985) cita apenas um estudo.

Da mesma forma que na epidemiologia, nas décadas de 1970 e 1980, os cientistas sociais que trabal havam no setor saúde no Brasil, na sua maioria, produziram um saber cuja matriz, com poucas exceções, se restringia às teorias marxistas, no seu viés mais positivista, como 0 althusseriano. $\mathrm{O}$ u seja, podemos observar, abrindo o âmbito de abrangência de nossa 
análise, que essa matriz de pensamento althusseriano marcou uma tendência teórica da comunidade científica nacional na abordagem das ciências sociais e humanas, sobretudo as aplicadas.

Só a partir da metade dos anos 80 se iniciou um proposital investimento teórico-conceitual e metodológico em outras abordagens compreensivistas e dial etizantes das determinações e da subjetividade. Em relação ao marxismo, a forte influência de Althusser foi substituída pelo pensamento de Gramsci, cuja elaboração teórica se mostrava muito mais aberta em relação ao campo das idéias, da subjetividade e da história. Desde então, vão se configurando algumas tendências: (1) a crise ou o abandono (na maioria dos casos) dos marcos referenciais baseados nas ditas metanarrativas ou das macroteorias, tanto no campo das ciências sociais como da epidemiologia; (2) o aprofundamento da tendência tecnicista entre os epidemiologistas, diferenciando-se os que têm uma produção acadêmica mais contextualizada e os que reverenciam cada vez mais os poderes dos métodos e dos instrumentos; (3) a tendência mais compreensi vista na produção das ciências sociais e saúde; e (4) menos majoritariamente, mas com forte potencial de expressão, tentativas de encontro entre os profissionais de ambas as áreas para elaboração de estudos interdisciplinares, transdisciplinares e de triangulação de métodos.

Em termos de investimento conceitual, se a epidemiologia se caracteriza pela busca da sofisticação e mesmo de fetichização do método, as ciências sociais no campo da saúde têm seu rigor metodológico muitas vezes sacrificado pela constante incursão de neófitos que se auto-intitulam "pesquisadores sociais". 0 boom das pesquisas qualitativas nos anos 80-90 parece um bom exemplo dessa entrada, por vezes superficial, uma vez que inúmeros trabalhos pouco ultrapassam o nível do senso comum. Esse crescimento de aproximação das ciências sociais de cunho compreensivo mostra um certo mal-estar dos estudiosos da área de saúde quanto ao tecnicismo e ao objetivismo. Porém, os mecanismos de regulação da prática científica nos dois campos parecem ser bastante distintos. M inayo (1998) trabalha essa questão num artigo sobre os diferentes graus de inclusão da antropologia no setor. A seu ver, tratase de um movimento positivo, mas complexo e diversificado de expansão, que necessita ser analisado em suas múltiplas dimensões.
M erecem atenção os questionamentos que freqüentemente têm sido feitos aos cientistas sociais pelos demais profissionais de saúde. Ao lado do reconhecimento da importância da abordagem das ciências sociais para o debate das estruturas e práticas que alicerçam o setor saúde, há uma crítica contundente em relação à pouca potencialidade de aplicação prática de seus conhecimentos. Embora essa observação seja generalizante, reflete a dificuldade de muitos profissionais da área em ultrapassar o formato das análises de alto nível de abstração teórica, mas pouco propositivas, distantes dos problemas imediatos e ausentes de uma perspectiva de ação que o campo da saúde demanda. Os representantes dessa postura mais distanciada argumentam que o papel do cientista social é teorizar, produzir conhecimento, refletir criticamente práticas, ideologias e saberes institucionalizados. Portanto, não Ihe cabe resolver problemas práticos ou dar um receituário para solucionar questões do cotidiano. As duas perspectivas tensionam 0 antigo debate sobre o papel da ciência, da técnica e o que seja a construção de uma tecnociência (modelo mais difundido no campo da saúde). Por outro lado, colocam em jogo o sentido praxiológico da ciência (J apiassu, 1976).

No sentido dos questionamentos tratados no parágrafo anterior, Wright Mills em sua obra clássica I maginação sociológica (1971) faz uma crítica radical ao distanciamento dos cientistas sociais, dizendo que seu papel deveria ser o de evidenciar, para seus contemporâneos, a significação da dinâmica da sociedade em que vivem e o sentido de sua participação específica. A "utilidade" da ciência estaria dada pela sua capacidade de transformar os grandes problemas sociais que o povo vive, em questões públicas a favor de mudanças sociais, colaborando para que os cidadãos informados sejam capazes de sair de seus limites individuais e de se sentir parte de uma história à qual sua biografia está estreitamente vinculada. A crítica central de W right M ills é sobre a falta de perspectiva epistemológica dos que se empenham escrupulosamente na construção de modelos matemáticos para seus dados e se mostram totalmente incapazes de fazer uma análise sociológica dos indicadores que geram. 0 escrúpulo profissional tão propalado pelos positivistas, que consiste em não interpretar fato ou processo algum que não possa ser comprovado com dados matemáticos (leia-se, "matemáticos" como sinônimo de "científicos"), na verdade se 
configurava, para Mills, como um serviço ao poder dos governos e das empresas, visando legitimar suas decisões (M ills, 1971).

Da mesma forma que W right M ills, Adorno \& H orkheimer (1991), dois expoentes da chamada sociologia crítica da Alemanha, desenvolveram uma contundente análise sobre a proliferação, em proporção geométrica, dos estudos quantitativos provenientes de dados secundários, nas ciências sociais em geral. Qualificando essa forma de trabal ho como "sociologia americana", os autores questionam a "reificação" ou a "fetichização" do método em detrimento da teoria. No mesmo rumo de Mills, reafirmam que a moda da sociologia, refém da quantificação e que mede até o inquantificável, não a torna nem uma ciência nem mais científica. De acordo com o ponto de vista dos dois autores, muitos investigadores não estão preocupados em fazer perguntas fundamentais e relevantes para a sociedade, em seus objetos de estudo, e sim, vivem obcecados pelo rigor das técnicas usadas. Isso os leva, freqüentemente, a efetuar grandes investimentos metodológicos, para responder a questões medíocres. A pobreza das perguntas iniciais, por causa do seu distanciamento das realidades empíricas, os conduz a resultados tecnicamente corretos, mas pífios.

\section{Propostas de articulação}

Como dissemos, no caput deste trabalho, a associação profícua entre epidemiologia e ciências sociais se dá quando existem (sendo na mesma pessoa, ou em pessoas associadas) cientistas sociais e epidemiologistas dispostos a uma relação profissional dialógica e respeitosa, e quando nesse encontro se articulam estudos que tratam da magnitude dos fenômenos e da análise da historicidade, das relações, das representações e da lógica interna dos processos e dos grupos trabalhados. Em tais circunstâncias, as ciências sociais têm um papel fundamental de historicização e crítica de conceitos e categorias e de aproximação e diferenciação do seu uso nas duas áreas de conhecimento. U sando apenas um exemplo, tomando como central os conceitos de população, risco, saúde e doença, desigualdade, qualquer processo de aproximação entre epidemiologia e ciências sociais partiria da problematização desses conceitos em sua especificidade histórica. N enhum deles é um dado, e seu significado costuma ser apropriado diferentemente por ambas as áreas.

É óbvio, como vimos mostrando em diversos trabalhos (M inayo, 1991; 1996; M inayo \& Cruz N eto, 1999; M inayo \& Sanchez, 1995), que as condições de possibilidades desse encontro, em primeiro lugar, se devem à vontade dos pesquisadores de ambas as áreas de dialogarem; da sua compreensão sobre a incompletude da unidisciplinaridade para analisar processos sociais e, especificamente, os de saúde e doença; e do esforço de problematizar conceitos, categorias e produzir um tipo de conhecimento que parte de várias disciplinas. A contribuição da interação entre ciências sociais e epidemiologia provém, justamente, de suas diferenças. Por um lado, existe a possibilidade de compreensão em profundidade dos valores, práticas, lógicas de ação, crenças, hábitos, atitudes e relações de grupos e indivíduos sobre a saúde, a doença, as terapêuticas, as políticas, programas e demais ações protagonizadas pelos serviços de saúde. E, por outro lado, a leitura epidemiológica da explicação em extensão de como esses sujeitos, agregados em um nível populacional, tornam-se expostos ou vulneráveis a eventos ou processos que colocam em risco sua saúde, como adoecem, como e com qual magnitude demandam tratamento e atenção. $M$ ais que pares de oposições, as ciências sociais e a epidemiologia traduzem, cada qual a sua maneira, as articulações entre o singular, o individual e o coletivo presentes nos processos de saúde-doença (Deslandes e Assis, 2002). A interação dialógica entre ambos aportes (e não por justaposição ou subordinação de um desses campos) constitui um avanço inegável para a compreensão dos problemas de saúde.

Para a prática interdisciplinar o exercício teórico disciplinar étão fundamental quanto 0 diálogo entre as diferentes áreas. Contudo, concordamos com Japiassu (1976), ao del egar ao debate epistemológico o principal fio dessa tessitura. A articulação entre diferentes campos de saber só é possível se passar por traduções das distintas lógicas e critérios de cientificidade, de uma hermenêutica do modus operandi de cada metodologia e da arquitetura dos conceitos que cada teoria de referência apresenta. Sem esse metadiálogo, os praticantes das diferentes tradições científicas estarão restritos ao infrutífero debate dos limites desse ou daquele conceito e de sua operacionalização ou se reduzem a justapor métodos.

Tomemos como exemplo as pesquisas sobre comportamentos e práticas de risco fre- 
qüentes na área de atuação da prevenção das Dst e Aids. 0 conceito de risco, como alerta H ayes, (1992) não tem fronteiras acadêmicas definidas, consequentemente são comuns as lacunas de coerência conceitual nas distintas produções sobre a temática. Pode tanto ser abordado pela epidemiologia (e é um de seus conceitos centrais) como pela sociologia, pelas ciências políticas, economia e antropologia. Risco é uma noção que se tornou popular no século 70 e que podia designar, numa lógica de jogos de azar, a probabilidade de um evento ocorrer. Segundo o autor, o conceito de risco estaria, hoje, inteiramente associado a resultados negativos do ponto de vista da epidemiologia. O "paradigma individual", hegemônico nas abordagens epidemiológicas sobre comportamentos de risco, tem como pressuposto que o indivíduo devidamente informado poderia escolher racional mente, diante das muitas opções de ações, aquela que não Ihe traria danos. No entanto, para a antropologia, com raras exceções - uma é a que realiza M ary Douglas (1970), para quem risco é sinônimo de perigo - , o termo faz parte do campo semântico da liberdade de escolha (Bloor, 1993), e até como sentido do existir, na medida em que qualquer decisão na vida implica risco (Deslandes e Assis, 2002).

Portanto, em lugar de discutir as diferenças da abordagem desse conceito parece ser mais profícuo compreender as lógicas disciplinares que o interpretam. Sua definição pelas ciências sociais parte do princípio que os sujeitos possuem consciência histórica e capacidade de interpretar e negociar os papéis que Ihes são atribuídos. Igualmente, dão significado às relações que vivenciam no seu cotidiano, absorvendo, a seu modo, as influências de seu grupo ou da rede de suas relações, da mídia e de outros portavozes da sua cultura. Essa construção de sentido é, por definição, coletiva e histórica, ainda que apropriada de forma diferente pelos indivíduos e grupos. Por conseqüência lógica, os instrumentos metodológicos empregados para conhecimento das percepções e práticas de risco buscam incluir as dinâmicas sociais (estruturas, rede de relações e influências e representações) que propiciam um determinado comportamento de risco. A preocupação é, então, captar e qualificar essa dinâmica e não somente descrevê-la sob a forma de teias causais de variáveis.

U m exemplo do que vem ocorrendo e demonstra as possi bilidades de interfertilização dos dois campos pode ser visto na já citada revisão sobre "violência e acidentes", elaborada por Souza e M inayo (2001). Se de um lado, evidenciam que metade dos trabal hos de epidemiologia pode ser classificada como a-teórica, as autoras ressaltam o indiscutível avanço na construção de estratégicas de cunho quantitativo-qual itativo e empírico, reunindo cientistas sociais e epidemiologistas em $41 \%$ dos trabaIhos. Assim como a tendência crescente de triangulação entre métodos quantitativo e qualitativo nos estudos epidemiológicos e nos de base sociológica ou antropológica que correspondem a $16 \%$ do total, o que não se verificou na produção intelectual até a década de 1980.

\section{Conclusões}

Entendemos que, no Brasil e na América Latina, temos dificuldades e potencialidades na articulação e na interfertilização disciplinar da epidemiologia pelas ciências sociais e vice-versa. Os problemas para a efetivação desse encontro são muitos: de ordem conceitual; de ordem metodológica e, sobretudo, de ordem histórica e cultural e até emocional. M uitas vezes, a defesa acirrada da pureza de uma disciplina esconde dificuldades dos pesquisadores em dialogar pessoal e teoricamente. Ou seja, as barreiras não são só do nível racional, elas impregnam o nicho seguro que a visão disciplinar oferece.

Por outro lado, sabemos que, para se reunirem conhecimentos, é preciso aprofundar concomitantemente os conceitos disciplinares, de tal forma que possam ser confrontados e enriquecidos transversalmente. I sso quer dizer que é preciso ter segurança em ambas as áreas para se criar interdisciplinaridade. Portanto, saudamos os pesquisadores que estão encontrando estratégias de romper as barreiras e ampliar as fronteiras do conhecimento, sem abrir mão do rigor e da competência. Terminamos com o significativo argumento de Almeida FiIho (2000):

É imperativo abrir a ciência epidemiológica à investi gação dos aspectos simbólicos ( tais como valor, relevância e significado) do risco e seus de terminantes. Se tomamos esta abordagem contextual até suas últimas conseqüências lógicas, podemos dizer que "fatores de risco sociais" nada mais são que a expressão do modo de vida de grupos populacionais. Assim, para dar conta do grande desafio de desenvolver uma epidemiolo- 
gia do modo de vida, precisamos, portanto, empreender uma reavaliação metodológica radical da nossa disciplina.

Será que os cientistas sociais da saúde pensam da mesma forma que o referido autor, na sua possível articulação com os epidemiologistas? Enquanto essas questões se ausentarem da pauta dos estudos em saúde, distante estaremos de descobrir a "caixa-preta de vagos contornos" (Carvalho, 2002) que não apenas se conforma pelo social, mas principalmente pelas formas como eleé percebido, vivenciado, elaborado e externalizado pelos indivíduos.

\section{Referências bibliográficas}

Adorno TW \& Horkheimer M 1991. Sociológica. Ediciones Taurus, Madri.

Almeida Filho N 1989. Epidemiologia sem números: uma introdução crítica à ciência epidemiológica. Editora Campus, Rio de Janeiro.

Almeida Filho N 2000. A ciência da saúde. Editora Hucitec, São Paulo.

Assis SG 1999. Traçando caminhos em uma sociedade violenta: a vida de jovens infratores e seus irmãos não infratores. Fiocruz, Rio de Janeiro.

Assis SG \& Constantino P 2001. Filhas do mundo: infração juvenil feminina no Rio de Janeiro. Fiocruz, Rio de Janeiro.

Bloor M et al. 1993. HIV-related risk practices among Glasgow male prostitutes: reframing concepts of risk behavior. M edical Anthropology Quarterly 7(2):152169.

Barreto M L 1990. A epidemiologia, sua história e crises: notas para pensar o futuro, pp. 19-38. In DC Costa (org.). Epidemiologia, teoria e objeto. Editora Hucitec, São Paulo.

Breilh J 1979 Epidemiología: economía, medicina y política. Ediciones de la U niversidad Central de Ecuador, Quito.

Breilh J \& Granda E 1985. Os novos rumos da epidemiologia, pp. 241-253. In ED N unes (org.). As ciências sociais e saúde na América Latina: tendências e perspectivas. Opas, Brasília

Canesqui AM 1998. As ciências sociais e a saúde. Editora Hucitec, São Paulo.

Carvalho DM 2002. Epidemiologia, história e fundamentos, pp. 3-14. In RA M edronho et al. (orgs.). Epidemiologia. Editora Atheneu, São Paulo.

Czeresnia D, Gadelha AM, Coimbra Jr CEA, Stotz EN \&
Castiel L 2000. Integração entre epidemiologia e antropologia. História, ciência e saúde 6(3):689-705.

Costa DC \& Costa NR 1990. Teoria do conhecimento e epidemiologia. Um convite à leitura de John Snow, pp. 167-202. In DC Costa (org.). Epidemiologia, teoria e objeto. Editora Hucitec, São Paulo.

Deslandes SF \& Assis SG 2002. Abordagens quantitativa e qualitativa em saúde: 0 diálogo das diferenças, pp. 195-226. In M CS M inayo \& SF Deslandes (orgs.). Caminhos do pensamento: epistemologia e método. Fiocruz, Rio de Janeiro.

Deslandes SF M endonça EA, Caiaffa WT \& Doneda D 2002. As concepções de risco e de prevenção segundo a ótica dos usuários de drogas injetáveis. Cadernos de Saúde Pública 18(1):141-151.

Douglas M 1970. Pureza e perigo. Editora Perspectiva, São Paulo.

Durkheim E 1980. Durkheim. Coleção Pensadores. Editora Abril, São Paulo.

Engels F 1977. The condition of the working class in England. ( $3 a$ ed.). Progress Publishers, M oscou.

Forget $\mathrm{G} \&$ Lebel J 2001. An ecosystem approach to human health. International Journal of O ccupational and Environmental $\mathrm{H}$ ealth 7(2):3-38.

Goldberg M 1990. Este obscuro objeto da epidemiologia, pp. 87-136. In DC Costa (org.). Epidemiologia, teoria e objeto. Editora H ucitec, São Paulo.

Gonçalves RBM 1990. Reflexão sobre a articulação entre a investigação epidemiológica e a prática médica a propósito das doenças crônico-degenerativas, pp. 39-86. In DC Costa (org.). Epidemiologia teoria e objeto. Editora H ucitec, São Paulo.

Habermas 1987. Teoria de la acción comunicativa. Editora Taurus, M adri. 
H ayes M V 1992. On the epistemology of risk: language, logic and social science. Social Sciences and M edicine 35(4):401- 407.

Japiassu H 1976. Interdisciplinaridade e patologia do saber. Imago, Rio de Janeiro.

Kleinbaum DG, Kupper LL \& M orgenstern H 1982. Epidemiologic research: principles and quantitative methods. Lifetime Learning, Belmont.

Laurell AC 1977. Algunos problemas teóricos y conceptuales de la epidemiologia social. Revista CentroAmericana de Ciencias de la Salud 3(5):79-97.

Last J 1983. A Dictionary of Epidemiology. Oxford University Press, N ova York.

Lilienfeld A 1976. Foundations of epidemiology. Oxford University Press, N ova York.

M acM ahon B, Ipsen J \& Pugh TF 1969. M étodos de epidemiologia. Prensa M édica M exicana, M éxico.

M ckeown T \& Löwe C 1979. Introducción a la medicina social. Siglo XXI, M éxico.

Medronho RA et al. 2002. Epidemiologia. Editora Atheneu, São Paulo.

M erton T 1970. Estrutura e função. Editora Zahar, Rio de Janeiro.

M iettinen 0 1985. Theoretical epidemiology. John Wiley and Sons Editions, N ova York.

Mills W 1971 A imaginação sociológica. Editora Zahar, Rio de Janeiro.

M inayo M CS 1991. Interdisciplinaridade: uma questão que atravessa o saber, o poder e o mundo vivido. M edicina 24(2):233-238.

M inayo M CS 1996. Interdisciplinaridade: funcionalidade ou utopia? Saúde e Sociedade, vol.3(2):5-21.

M inayo MCS 1998. Construção da identidade da antropologia na área de saúde: 0 caso brasileiro, pp. 5872. In P Alves \& M Cardoso (orgs.). Traçando identidades e explorando fronteiras. Editora Relume Dumará, Rio de Janeiro.

M inayo M CS 2000. Ciências sociais e saúde no Brasil: vida longa e recente relevância. Saúde em D ebate 24 (55): 44-53.

M inayo M CS 2001. Estrutura e sujeito, determinismo e protagonismo histórico: uma reflexão sobre a práxis da saúde coletiva. Ciência \& Saúde Coletiva 6(1):719.

M inayo M CS 2002. 0 enfoque ecossistêmico de saúde e qualidade de vida, pp. 72-89. In M CS M inayo \& AF $M$ iranda (orgs.). Saúde e ambiente sustentável: estreitando nós. Fiocruz, Rio de Janeiro.

M inayo M CS et al. 2000. Fala galera: juventude, cidadania e violência. Editora Garamond, Rio de Janeiro.

M inayo M CS \& Cruz N eto 0 1999. Triangulación de métodos en la evaluación de programas y servicios de salud, pp. 65-80. In M Bronfman \& R Castro (coords.). Salud, cambio social y política: perspectivas desde América Latina. Edamex-Instituto Nacional de Salud Pública, M éxico.

M inayo M CS \& M inayo-Gomez C 2002. Difíceis e necessárias relações entre métodos quantitativos e qualitativos. (no prelo na Fiocruz, na coletânea organizada por Paulette Goldemberg).

M inayo, M CS \& Sanchez O 1993. Quantitativo \& qualitativo: oposição ou complementaridade? Cadernos de Saúde Pública 9(3):239-262.

N unes ED 1985 As ciências sociais e saúde na América Latina. Editora OPAS, Brasília.

Nunes ED 1999. Sociologia da saúde. Editora H ucitec, São Paulo.

Pereira M G 2000. Epidemiologia: teoria e prática. Guanabara Koogan, Brasília.

Rhodes T 1997. Risk theory in epidemic times: sex, drugs and the social organization of risk behavior. Sociology of $\mathrm{H}$ ealth \& IIIness 19(2):208-227.

Sabroza PC 1990. Prefácio, pp. 7-12. In DC Costa (org.). Epidemiologia, teoria e objeto. Editora H ucitec, São Paulo.

Sfez L 1997. La Santé Parfaite. Éditions du Seuil, Paris.

Snow J 1967. Sobre a maneira de transmissão do cólera. Edições U said, Rio de Janeiro.

Souza ER \& M inayo, M CS 2001. Análise das tendências da produção acadêmica sobre acidentes e violências. Claves-Ensp-Fiocruz, Rio de Janeiro. (M imeo).

Stouffer S 1931. An experimental comparison of statistical and case history methods of attitude research. American Sociological Society 25:154-156.

Waltners-Toews D 2001. An ecosystem approach to health and its implications to tropical and emerging diseases. Cadernos de Saúde Pública 17(supl. 1):7-36.

Zielhuis GA \& Kiemeney ALM 2001. Social epidemiology? No way. International Journal of Epidemiology 30:43-44.

Artigo apresentado em 5/9/2002

Aprovado em 31/10/2002

Versão final apresentada em 12/1/2002 